\title{
Migrações em áreas de agronegócio
}

\author{
Moacir Palmeira* \\ Beatriz M. A. de Heredia**
}

Nas últimas três décadas, a produção de commodities agrícolas no Brasil, até então restrita a áreas do Sul e do Sudeste, expandiu-se em direção ao norte, ocupando as áreas de cerrado ${ }^{1} \mathrm{em}$ várias frentes, atingindo o extremo norte do país, inclusive alguns pontos da floresta amazônica. Hoje, as modernas plantações de soja, algodão, cana-de-açúcar ou do café certificado (o chamado "café do cerrado") estão, sobretudo, nos estados que se estendem de Minas Gerais ao Pará, chegando já ao Amapá e a Roraima, e a moderna fruticultura para exportação divide-se entre a borda oriental da faixa de cerrado e algumas áreas de caatinga ${ }^{2}$ no Nordeste, onde a irrigação tornou possível o seu cultivo.

Até os anos 1970, as terras dos estados do Centro-Oeste, hoje cobertas pela soja, eram consideradas inadequadas para agricultura e eram ocupadas por populações indígenas e pequenos posseiros, além de algumas fazendas de pecuária extensiva dispersas ao longo de um vasto território. Já regiões como o Triângulo Mineiro e o Oeste Baiano eram áreas tradicionalmente ocupadas pela criação de gado, praticada principalmente em grandes fazendas, e cultivos ligados à pequena produção agrícola destinada ao consumo local e regional. Se, nas suas chapadas, usadas para o criatório, havia uma população rarefeita, seus vales, ao contrário daqueles do Centro-Oeste, abrigavam uma população de certa monta, no caso do Triângulo cidades de importância econômica, sendo a região ela própria cortada por estradas que ligavam o Sul e o Sudeste ao centro e ao norte do país.

* Prof. PPGAS/Museu Nacional/UFRJ e Pesquisador CNPq.

**Prof". PPGAS/IFCS/UFRJ e Pesquisadora do CNPq. 
Os programas governamentais de ocupação dos cerrados desencadeados, com algumas variações, em diferentes estados, nos anos 1970, levariam a soja, uma espécie de produto estratégico nessa empreitada, a estados como Goiás, Minas Gerais (oeste e norte, além do Triângulo), Bahia (oeste baiano), Maranhão (sul) e Mato Grosso e estimulariam o cultivo, nessas áreas, de outros produtos para a exportação, sobre bases tecnológicas novas ${ }^{3}$. A soja, por uma série de razões, daria resultados muito favoráveis em termos de produção no Mato Grosso. Inicialmente experimentada em municípios do sudeste do estado atual ${ }^{4}$ como Rondonópolis e Primavera do Leste (hoje transformados em produtores de sementes) expandiuse para o norte ao longo do eixo da rodovia BR-163, que liga a capital Cuiabá a Santarém, no estado do Pará. Essa área que hoje é considerada como área de soja "consolidada" (BERNARDES, 2005), coexiste com pelo menos duas importantes áreas de expansão: a Chapada dos Parecis e o vale do rio Xingu. (Vide Tabela 1).

Como pode ser observado, não se trata da transferência do produto de uma região para outra. A produção da Região Sul, que em 1965 representava a quase totalidade da produção do país, continuaria a crescer ao longo das décadas em que o produto se dissemina por outras regiões. Apenas em 2005 sua área colhida será superada pela do Centro-Oeste. No Centro-Oeste, o grande produtor da soja será o estado de Mato Grosso, que concentra mais da metade da produção de toda a região, seguido de perto pelos estados do Rio Grande do Sul e do Paraná. (Vide Tabela 2)

Em Minas Gerais, na região do Triângulo Mineiro, o sucesso da soja, produto ainda hoje dominante em municípios como Iraí de Minas, Uberaba e Uberlândia, coexistiria com os bons resultados de outros produtos, como o café na sub-região do Alto Paranaíba. ${ }^{5}$ O café tem uma história mais longa e conhecida. O Brasil segue como seu primeiro produtor mundial e até o início dos anos 2000 aquele produto liderava a pauta de exportações agrícolas do país e, mesmo depois de superado por outros produtos, sua produção continua crescendo (SAES, 2004).

Produto cultivado há mais de um século no estado, que, na última metade do século XX teria a região montanhosa sul de Minas entre as maiores produtoras do país, o café seria introduzido na área de Araguari em 1972 (OLIVEIRA, 1991, p. 41). As novas condições de produção geradas pelos programas de ocupação das terras planas do cerrado - correção de solos, irrigação, uso de defensivos e adubos químicos, máquinas - abririam perspectivas muito favoráveis ao cultivo do café certificado para exportação que assumiria o rótulo "café do cerrado". Impondo-se rapidamente na região, já apresentava resultados animadores nos anos 1970 nos municípios em torno de Patrocínio e Araguari, atingindo seu ápice em 1990-2000. Hoje enfrenta na região a concorrência de produtos como a cana-de-açúcar, mas continua a ter uma posição importante na economia, movimentando capitais expressivos e apresentando um crescimento populacional marcante. 
Essas áreas de expansão do que passou a ser rotulado, no Brasil, de agronegócio, são áreas de forte expansão demográfica. Mesmo que em termos absolutos o volume das populações que as ocupam na atualidade não configurem, como advertia George Martine nos anos 1980 (MARTINE,1984) para as fronteiras agrícolas de então, uma espécie de válvula de escape demográfico aos que procuravam as grandes cidades, em termos relativos há uma transformação significativa, sem que isso signifique homogeneidade entre as diferentes regiões e, muito menos, uma expansão linear.

O objetivo deste artigo é tentar entender o significado dessa dinâmica populacional, através da comparação entre duas áreas associadas exemplarmente ao cultivo dos dois produtos que mencionamos - soja e café - por ambos terem um lugar importante no conjunto das commodities agrícolas: a área de produção de soja em torno da rodovia BR 163, no Mato Grosso, e aquela do chamado "café do cerrado" no Triângulo Mineiro/Alto Paranaíba, Minas Gerais ${ }^{6}$. Sendo a primeira uma área de ocupação tida como recente e de cultivo quase exclusivo da soja, e a segunda uma área de ocupação secular e cultivos diversificados, a comparação pode ser ainda mais rica ${ }^{7}$.

\section{$* * *$}

O contraste entre as taxas de crescimento populacional do país, de dois dos estados em que o agronegócio se desenvolve e das regiões que escolhemos estudar dá uma ideia das transformações demográficas associadas a tal empreendimento. (Vide Tabela 3).

As coisas se tornam ainda mais nítidas quando consideramos o nível local, os municípios em torno dos quais concentramos nossa pesquisa. Podemos ver, por exemplo, como Sorriso e Lucas do Rio Verde, núcleos urbanos gerados pela produção de soja nos anos 1970 e 1980 e transformados em municípios no começo dos anos 1990, apresentam taxas de crescimento anual da população muito superiores às do estado e do país. (Vide Tabela 4).

\section{$* * *$}

Esse crescimento demográfico deve-se, basicamente, à migração. Se no caso de Mato Grosso isso é, por assim dizer, autoevidente, considerando a quantidade mínima de pessoas que, no início dos anos 1970, habitavam a região que viria a ser ocupada pela soja, no caso do Triângulo Mineiro, região de ocupação antiga e de atividade econômica diversificada, isso não é tão explícito. Mas quando restringimos o nosso foco de comparação às atividades agrícolas e, especificamente, ao café, nos defrontamos, sobre uma base territorial bem menor, com populações do mesmo porte das que encontramos nos municípios do Alto Teles Pires, em que os migrantes têm um peso significativo. Em Araguari, por exemplo, $60 \%$ das 2.718 pessoas que trabalhavam em 2000 no cultivo do café eram de fora do estado de Minas Gerais. (Vide Tabelas 5 e 6). 
O manejo dos dados estatísticos mostra que, em ambos os casos, esse acréscimo de população não só resulta de movimentos migratórios, mas de movimentos migratórios originados em grande parte, em outras regiões do país, em especial na Região Sul. Os naturais do Paraná, seguidos pelos do Rio Grande do Sul e de Santa Catarina, na região mato-grossense, e pelos paulistas, nos municípios estudados no Triângulo Mineiro, são majoritários em ambos os casos. A presença de migrantes vindos de estados de outras regiões, de outros municípios, do Mato Grosso inclusive, em Sorriso e Lucas do Rio Verde só crescerá a partir dos anos 1990, com o estabelecimento de um número importante de pessoas provenientes do Nordeste, em especial do Maranhão. Nos municípios do Triângulo, a migração de paranaenses e paulistas anda pari passu com a de nordestinos, onde os baianos se destacam (embora menos hegemônicos que os maranhenses em Mato Grosso) e ambas têm o seu pico nos mesmos anos 1990 (IBGE, Censo Demográfico, 2000).

Não parece, pois, casual que o "mapa social" elaborado pelos que vivem nessas regiões remeta ao local de nascimento efetivo ou suposto das pessoas a quem estão se referindo: "gaúchos" e "maranhenses" na área de soja em Mato Grosso; "paulistas" ou "paranaenses" e "baianos", além dos "mineiros" na área cafeeira do Triângulo Mineiro. ${ }^{8}$ É valendo-se desse tipo de classificação que as pessoas dos lugares estudados reportam a pesquisadores a história dos lugares onde vivem, que elas se localizam no cotidiano ("falei hoje com um maranhense"; "na festa só tinha gaúcho" ou "a fazenda é de um paranaense"; "encontrei um baiano na rodoviária") ou mesmo classificam os espaços de sua cidade ("bairros de gaúcho", os mais valorizados, e "bairros de maranhense", os de condições mais precárias, para ficarmos apenas com o exemplo de Mato Grosso), estabelecendo ou confirmando uma segregação geográfico-social que tem impressionado visitantes. Essa segregação se manifesta também nas imagens que os sulistas elaboram a respeito dos maranhenses (ou em Minas, os paranaenses acerca dos baianos) que concentram a seus olhos todos os vícios e são responsabilizados pela violência que estaria se instaurando nas cidades da região, sem que haja acusações tão contundentes na direção oposta. $O$ trabalho de campo nessas regiões, todavia, mostra que não há coincidência perfeita entre as classificações locais e as classificações estatísticas oficiais. Assim, ser considerado gaúcho não significa ter nascido no estado do Rio Grande do Sul e muito menos ter nascido nos pampas, como nos ensinam os dicionários. Se a maioria absoluta dos que vivem na área de soja que estudamos em Mato Grosso vem do Sul do Brasil, entre estes predominam, desde os primeiros momentos da ocupação, os nascidos no estado do Paraná e há também um grande volume de nascidos em Santa Catarina. "Gaúcho", às vezes, é intercambiável com "sulista", mas identidades associadas a outros estados específicos, como os majoritários paranaenses, não são socialmente correntes. Referências ao estado do Paraná e aos paranaenses aparecem, vez por outra, em placas singularizando casas comerciais - "Armazém Paraná" ou "Restaurante O Paranaense" -, no entanto, o proprietário continua a ser classificado como "gaúcho". 
No Triângulo Mineiro, em áreas dominantemente sojicultoras, como Iraí de Minas, município onde primeiro se estabeleceriam colonos do sul, apoiados por programas governamentais nos anos 1970, "gaúcho" opera como termo classificatório de modo semelhante a Mato Grosso. O mesmo parece ocorrer em municípios mais ao norte, onde, associados ao cultivo da soja ou de outros produtos, migrantes do sul são assim identificados ${ }^{9}$. Todavia, no conjunto do Triângulo Mineiro, onde os paranaenses, como no Alto Teles Pires, são migrantes majoritários e, em especial, nas áreas cafeicultoras, "paranaense" e/ou "paulista" é o termo que designa os que vêm do Sul ${ }^{10}$. O primeiro tende a prevalecer, ainda que, especificamente na área do café; os próprios paranaenses passam a se declarar "paulistas" de origem - se dizem de famílias cafeicultoras paulistas que teriam se deslocado para o Paraná e que, mais recentemente, teriam inaugurado o cultivo do café do cerrado no Triângulo - assinalando certa "tradição" de produtores de café, que seria a sua marca.

Uma explicação concebível para essa dissociação entre identidade vinculada à origem e a natalidade efetiva seria a de se estar confundindo o local de procedência com o local de nascimento. Mas nem em termos estatísticos, nem em termos das formulações locais isso se sustenta. Mesmo que uma grande quantidade de migrantes, nos dois casos estudados, tenha provindo de estados ou municípios diferentes daqueles de origem, os censos separam, com clareza, estado e município de origem de estado e município de nascimento. $E$, quando se trata das representações das populações estudadas, fica claro que as pessoas, na maior parte das vezes, englobam sem problemas um paranaense ou um catarinense na categoria "gaúcho", mesmo sabendo que ele não é nascido no Rio Grande. 0 que parece estar em jogo são certos atributos sociais, que, por sua vez, não são fixos, variam ${ }^{11}$.

A primeira impressão que se tem é que essas classificações servem para agrupar, em dois conjuntos distintos, proprietários rurais e outros agentes sociais ligados ao mundo do agronegócio em oposição a migrantes nordestinos vinculados ao mundo do trabalho. Afinal de contas, a confirmar essa aproximação estariam as estatísticas que nos mostram que, nos dois municípios de Mato Grosso, todos os proprietários rurais são provenientes da Região Sul e que, naqueles de Minas Gerais, onde os mineiros representam a maioria deles, há um percentual expressivo de proprietários de terras do sul do país enquanto são pouquíssimos os nordestinos em tal condição. Mas essa nitidez se desfaz quando verificamos nessas mesmas estatísticas que os sulistas também são majoritários entre os empregados na agricultura, tanto entre os que têm carteira de trabalho assinada, quanto entre os que não têm contratos de trabalho formalizados, identificados, via de regra, como os trabalhadores com piores condições de vida e trabalho. Por outro lado, a observação direta das áreas evidencia uma grande diversidade no interior das categorias sociais "produtores" e "trabalhadores". Entre os "produtores": "empresários"12, "agricultores", "chacareiros", "assentados". Entre os trabalhadores: "braçais", "operadores de máquinas" e o "pessoal das oficinas", 
dentro das fazendas; além da massa dos trabalhadores fixos ou temporários, que, em boa parte, escapa ao filtro das classificações estatísticas, que circulam entre os bairros periféricos das cidades e as fazendas, entre atividades agrícolas e o emprego nos silos e indústrias de beneficiamento nos núcleos urbanos. Complexificando mais ainda esse quadro, a constatação de que "assentados" e "chacareiros", que são proprietários de lotes de terra relativamente pequenos ${ }^{13}$, trabalham diretamente suas terras com suas famílias, mas também "agricultores" com superfícies de terra expressivas ${ }^{14}$ não apenas gerenciam suas propriedades como também "sobem no trator", quando não executam outros trabalhos junto com membros da família e alguns empregados. E, no outro extremo, a constatação de que os que migram do Maranhão para Mato Grosso, para trabalhar nas plantações de soja, não são os que nos lugares de origem se encontram em pior situação econômica, havendo casos de proprietários de terras com trabalhadores fixos em suas fazendas naquele estado que descem para o último, buscando, através do trabalho assalariado nas plantações de soja, recursos monetários para expandir seus negócios no estado de origem (RUMSTAIN, 2009) ${ }^{15}$

A consideração dessa complexidade leva-nos a questionar a ideia de que esse encontro de populações possa ser explicado simplesmente em torno de conexões causais lineares, como a suposição de que o agronegócio, abrindo perspectivas de lucro para uns e de emprego para outros, estaria atraindo excedentes populacionais de outras regiões. Pelo menos nas áreas que estudamos os "fluxos migratórios" não parecem ser exatamente complementares. Os próprios grandes conjuntos em que a sociedade se vê dividida não preexistem à sua convivência, ainda que algumas oposições entre as categorias que são acionadas e os atributos positivos ou negativos que a eles se associam pudessem existir previamente (como chamamos a atenção em nota sobre o estudo de Pierre Monbeig sobre São Paulo na primeira metade do século passado).

Um fato comum aos que vieram do sul do país é que esse deslocamento para Mato Grosso ou outros estados não representou uma primeira experiência. A grande maioria deles, para não dizer a quase totalidade, tinha experiência própria, à frente de suas famílias ou, no caso dos mais jovens, acompanhando a sua família de origem, de deslocamentos anteriores dentro da região sul e/ou deslocamentos ocorridos no interior do próprio estado onde hoje vivem, antes de chegar ao seu local atual de moradia. Esses deslocamentos, coletivos ou individuais, mas sempre geridos pela família, fizeram com que alguns dos atuais residentes na região estudada tenham deixado parentes mais ou menos próximos (pais, filhos, irmãos, tios, primos, etc.) nos locais de origem e também em regiões por onde passaram; estendendo-se essas redes, por vezes, a áreas mais à frente, ainda em processo de incorporação à produção agrícola "moderna". As relações com esses parentes são atualizadas de várias maneiras, uma delas sendo as visitas no período da entressafra ou nas festas de final do ano. Esses mecanismos que funcionaram no passado continuam a ser acionados e a condicionar as decisões de mudança. A perspectiva de deslocamento parece ser tão essencial ao planejamento da 
reprodução social dessas famílias quanto a existência de terra para exercer a sua atividade produtiva. Longe de ser alguma coisa que só se coloca em situaçõeslimite, a possibilidade de deslocamento para outro lugar, onde, sendo os primeiros a chegar, possam ter acesso a uma parcela de terra ou a uma parcela maior, é avaliada cotidianamente (DESCONSI, 2009). Mesmo os que se deslocam como trabalhadores assalariados, em sua maioria, obedecem a uma estratégia familiar e têm a propriedade de uma parcela de terra, seja no mesmo local ou em locais mais distantes onde o preço da terra é menor, em seu horizonte.

Mesmo que também orientados por estratégias familiares, os deslocamentos de maranhenses para Mato Grosso e de baianos para Minas Gerais oferecem uma dinâmica distinta. Nem os municípios do Alto Teles Pires, nem aqueles do Triângulo Mineiro representam um ponto de chegada para uns e outros, nem a obtenção de terra nessas regiões, um objetivo maior. Para muitas famílias, fundamentalmente, a infraestrutura rodoviária aberta nas áreas de agronegócio é um meio de acesso ao mercado de trabalho em áreas agrícolas ou agroindustriais no centro, no sudeste e no sul do país. Essas famílias perfazem um trajeto que passa pelo trabalho temporário em diversas regiões do país, conforme a safra de diferentes produtos, retornando ao final a seus locais de origem. Assim, há maranhenses que trabalham na colheita de soja em Mato Grosso, dali seguem para a apanha de café no Triângulo Mineiro, deslocando-se posteriormente para São Paulo ou Paraná, para o corte de cana-de-açúcar ou para a colheita do algodão, retornando, ao final ao Maranhão, repetindo esse ciclo anualmente. O mesmo acontece com os baianos que trabalham, com alguma regularidade, na colheita de café em Minas Gerais, e que, uma vez acabado o ciclo agrícola desse produto, seguem roteiro similar ao dos maranhenses, antes de retornar a seus roçados no Nordeste. Tanto no caso dos "maranhenses" quanto no caso dos "baianos", mesmo que alguns acabem se estabelecendo nos lugares para onde se deslocam em busca de trabalho, com emprego na construção civil ou no pequeno comércio, prevalece o modelo de sua casa continuar sendo no estado de origem. Assim, a perspectiva de trabalho em uma região mais próxima da família e/ou a oferta de salários mais altos pode transformar aquele longo percurso em um movimento de idas e vindas entre a área de residência e área escolhida como local de trabalho, como parece estar acontecendo hoje em Mato Grosso. Os recursos obtidos no trabalho nas fazendas de Mato Grosso não são, neste caso, utilizados para a compra de terra ou de outros bens que permita aos maranhenses estabelecerem-se nesse estado, mas são canalizados, pelo menos idealmente, para o reforço da posição de suas famílias no Maranhão, o que pode incluir compra de terra ou gado, ou simplesmente o incremento do padrão de consumo dessas famílias (RUMSTAIN, 2009).

Se pudermos falar de conflito ou de disputa entre "gaúchos" e "maranhenses" no Mato Grosso da soja ou entre "paranaenses", "paulistas" e "baianos" no Triângulo do café do cerrado, diremos que estamos diante de uma "disputa imperfeita". Não se trata de uma disputa entre grupos assimétricos (como efetivamente são) por um mesmo objeto. Há sim uma disputa de "território", como assinalado na 
segregação espacial, mas de territórios que as estratégias familiares de uns e outros recortam de modo diverso. As modalidades de presença são distintas. Os sulistas, nos dois casos, querem estabelecer-se, e o estão fazendo, como em seu mundo. Sintomaticamente, em Mato Grosso eles se definem como os "do lugar", os "da terra", e, no Triângulo do café, se essa identificação continua sendo própria aos mineiros, há exemplos de disputa dessa condição por paranaenses (SOUZA JUNIOR, 2009). Mas o mundo e o lugar dos nordestinos é outro, é onde estão suas famílias. As fazendas de soja e de café são territórios de passagem, mesmo quando essa passagem se prolonga. São dois grupos em permanente movimento (maranhenses e baianos não são mais sedentários que os sulistas) que esbarram. 


\begin{tabular}{|c|c|c|c|c|c|c|}
\hline 옴 & 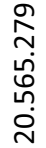 & 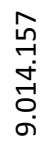 & 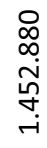 & $\begin{array}{l}\stackrel{\leftrightarrow}{\infty} \\
\stackrel{\infty}{*} \\
\stackrel{\forall}{\forall}\end{array}$ & $\begin{array}{l}\mu \\
\text { مٌ } \\
0 \\
0 \\
\text { m} \\
\end{array}$ & 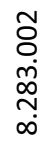 \\
\hline 옹 & \begin{tabular}{l}
\multirow{N}{\infty}{} \\
$\infty$ \\
$\infty$ \\
\multirow{\sigma}{*}{} \\
$\stackrel{N}{N}$
\end{tabular} & 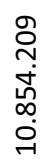 & $\begin{array}{l}\vec{b} \\
- \\
- \\
- \\
\dot{J} \\
-\end{array}$ & 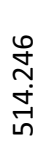 & 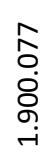 & $\begin{array}{l}\underset{\infty}{\infty} \\
\stackrel{-}{-1} \\
\stackrel{\sim}{N} \\
\underset{\infty}{0}\end{array}$ \\
\hline ষ্ণ & 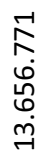 & 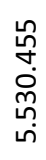 & \begin{tabular}{l}
0 \\
$\stackrel{0}{\circ}$ \\
\multirow{\infty}{\infty}{} \\
\multirow{\infty}{*}{}
\end{tabular} & $\begin{array}{l}\circ \\
\mathscr{\&} \\
\stackrel{+}{r}\end{array}$ & 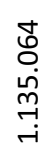 & 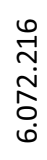 \\
\hline బૂ & 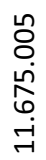 & 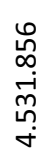 & 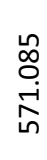 & $\begin{array}{l}\hat{\vec{b}} \\
\dot{\sim} \\
\dot{\sim}\end{array}$ & 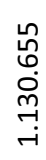 & 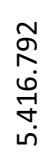 \\
\hline ᄋ్ & 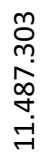 & $\begin{array}{l}m \\
\text { مٌ } \\
\stackrel{0}{\circ} \\
\infty \\
\infty \\
\dot{m}\end{array}$ & $\begin{array}{l}\vec{H} \\
\infty \\
\stackrel{0}{0} \\
\stackrel{m}{m}\end{array}$ & $\begin{array}{l}\text { ָे } \\
\text { ஸे }\end{array}$ & 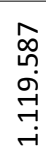 & $\begin{array}{l}\underset{\infty}{\infty} \\
\text { } \\
\underset{+}{+} \\
\dot{\sigma}\end{array}$ \\
\hline $\begin{array}{l}\stackrel{n}{\infty} \\
\stackrel{\infty}{\rightarrow}\end{array}$ & 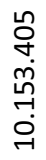 & 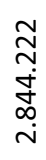 & 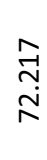 & 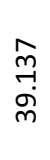 & 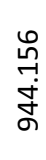 & 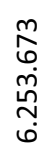 \\
\hline $\begin{array}{l}\stackrel{8}{\infty} \\
\stackrel{-}{\rightarrow}\end{array}$ & 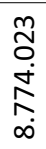 & 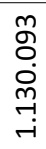 & 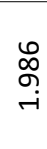 & $\stackrel{\infty}{\infty}$ & $\begin{array}{l}\stackrel{\mathscr{n}}{\sim} \\
\stackrel{n}{N}\end{array}$ & 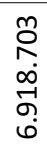 \\
\hline 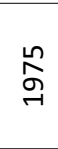 & 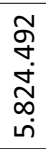 & $\begin{array}{l}\stackrel{\circ}{0} \\
\infty \\
\stackrel{\infty}{\sim} \\
\stackrel{\sim}{~}\end{array}$ & 定 & ' & $\stackrel{\hat{\sigma}}{\stackrel{\sim}{\sigma}}$ & 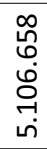 \\
\hline 옥 & $\begin{array}{l}\text { o } \\
\infty \\
\infty \\
\infty \\
\stackrel{1}{m} \\
\text { ri }\end{array}$ & 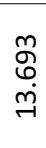 & $\underset{\sim}{\varphi}$ & ' & $\stackrel{\vec{m}}{\stackrel{\tilde{n}}{\sigma}}$ & 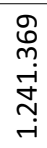 \\
\hline $\begin{array}{l}\text { ֻூ } \\
\stackrel{్}{-}\end{array}$ & $\begin{array}{l}\stackrel{\nabla}{\infty} \\
\infty \\
\dot{\sim} \\
\stackrel{\sim}{+}\end{array}$ & ষ্ণ & $\stackrel{ન ્}{\text { ம் }}$ & ' & 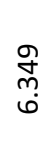 & $\begin{array}{l}\stackrel{ }{\mathcal{N}} \\
\stackrel{+}{+} \\
\stackrel{\sim}{*}\end{array}$ \\
\hline & $\begin{array}{l}\overline{\bar{n}} \\
\overline{\frac{0}{n}}\end{array}$ & 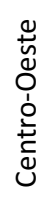 & 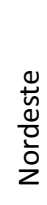 & $\begin{array}{l}\stackrel{ \pm}{ \pm} \\
\stackrel{0}{Z}\end{array}$ & 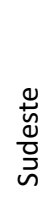 & $\overline{\bar{n}}$ \\
\hline
\end{tabular}




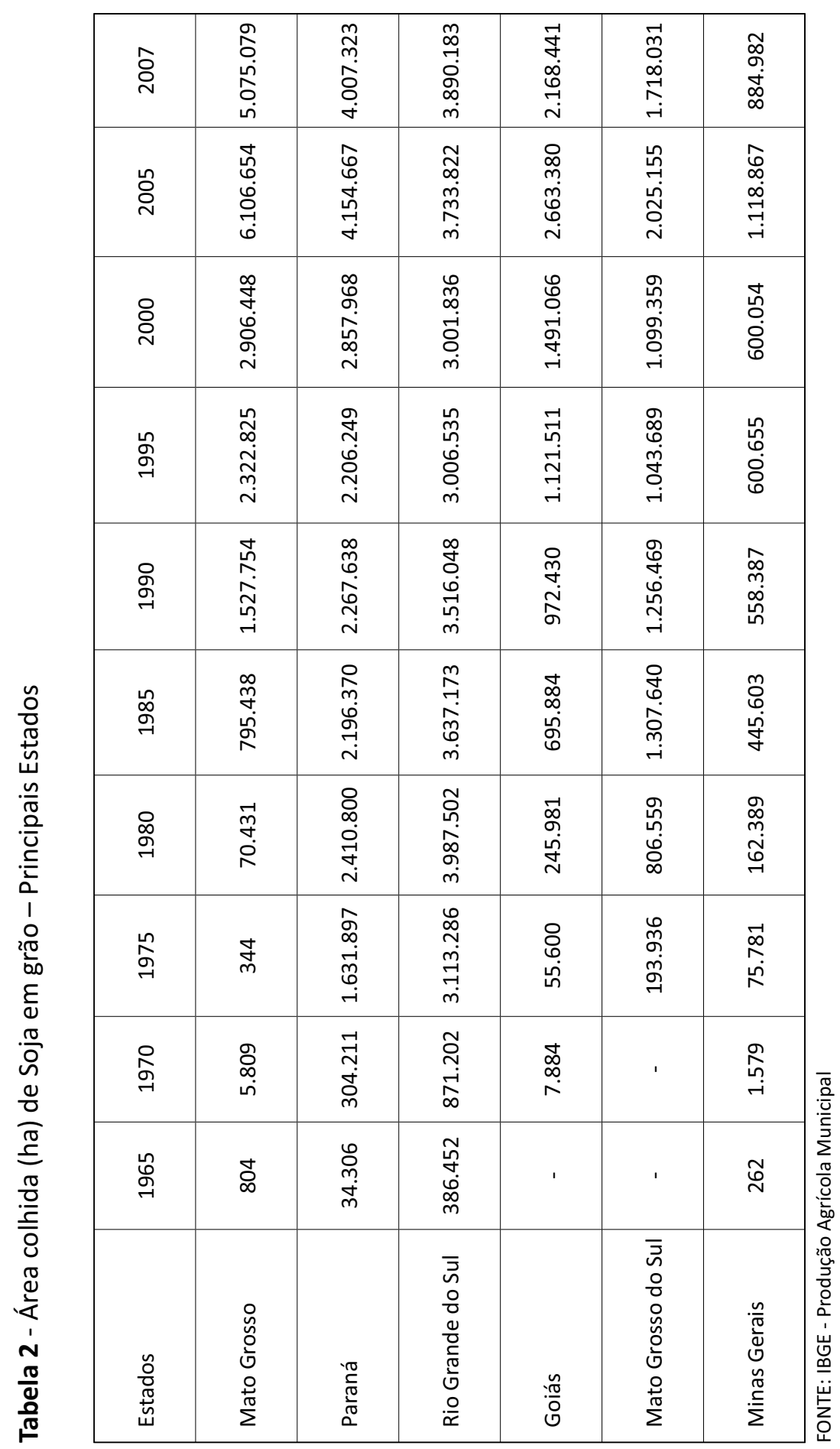




\begin{tabular}{|c|c|c|c|c|c|c|c|c|}
\hline \multirow{3}{*}{ 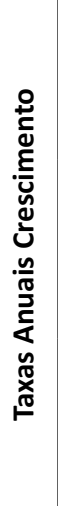 } & 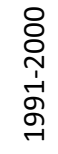 & $\begin{array}{l}\text { 今े } \\
\text { ơ }\end{array}$ & $\stackrel{\stackrel{\circ}{d}}{\text { N }}$ & $\begin{array}{c}\stackrel{\circ}{m} \\
\text { mे }\end{array}$ & $\begin{array}{l}\text { ठे } \\
\infty^{-}\end{array}$ & $\stackrel{\text { ১̊ }}{\stackrel{\text { ন }}{-}}$ & $\begin{array}{l}\stackrel{0}{\circ} \\
\text { - }\end{array}$ & $\stackrel{\stackrel{\circ}{\sim}}{\sim}$ \\
\hline & 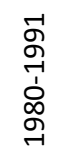 & ๙े & ஸ゚ & $\stackrel{\stackrel{\text { }}{\sim}}{\underset{\sim}{-}}$ & $\begin{array}{l}\stackrel{\circ}{\circ} \\
\text { ণे }\end{array}$ & ๙ิ̊ & $\begin{array}{l}\stackrel{0}{\dagger} \\
\text { - }\end{array}$ & $\begin{array}{l}\text { ○े } \\
\text { mं }\end{array}$ \\
\hline & $\begin{array}{l}0 \\
\infty \\
\stackrel{-}{7} \\
\stackrel{1}{0} \\
\text { م્ }\end{array}$ & ஸ̊ & $\begin{array}{l}\stackrel{\circ}{6} \\
\text { ఠే }\end{array}$ & $\begin{array}{l}\text { ১े } \\
\text { సે }\end{array}$ & $\begin{array}{l}\text { ठ̊ } \\
\text { のે }\end{array}$ & ㅇํㄱ & $\begin{array}{l}\text { ১े } \\
\text { i }\end{array}$ & $\underset{\sim}{\stackrel{\circ}{\sim}}$ \\
\hline \multirow{4}{*}{ 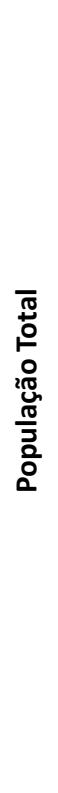 } & ঃ & 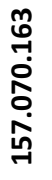 & 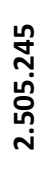 & 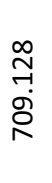 & $\begin{array}{l}\hat{n} \\
\text { ọ } \\
\text { 엄 }\end{array}$ & 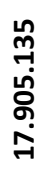 & $\begin{array}{c}\stackrel{\hat{m}}{N} \\
\stackrel{i}{\infty} \\
\stackrel{\infty}{-i}\end{array}$ & $\begin{array}{l}\text { No } \\
\text { O̦ } \\
\text { م }\end{array}$ \\
\hline & 음 & 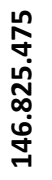 & 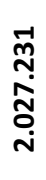 & 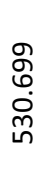 & $\begin{array}{l}\text { 円ి } \\
\infty \\
\text { ○் } \\
\text { மn }\end{array}$ & 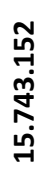 & 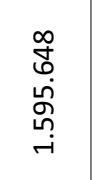 & $\begin{array}{l}\text { જூ } \\
6 \\
\dot{0} \\
\text { ம் }\end{array}$ \\
\hline & $\begin{array}{l}\stackrel{\infty}{\circ} \\
\stackrel{-}{-}\end{array}$ & 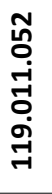 & 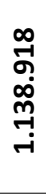 & 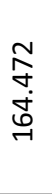 & $\begin{array}{l}\underset{g}{J} \\
\ddot{g} \\
\vec{H}\end{array}$ & 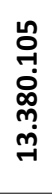 & 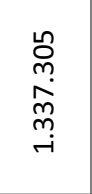 & 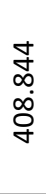 \\
\hline & $\begin{array}{l}\stackrel{\circ}{-} \\
\text { ㅇ }\end{array}$ & 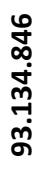 & 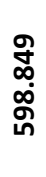 & 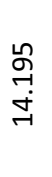 & مָ & 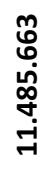 & 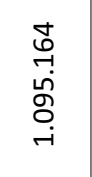 & $\begin{array}{l}\stackrel{-}{N} \\
\stackrel{ }{N}\end{array}$ \\
\hline . & 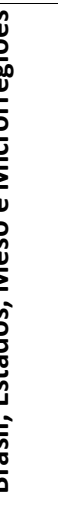 & $\begin{array}{l}\overline{\bar{n}} \\
\frac{\overline{0}}{\bar{\omega}}\end{array}$ & 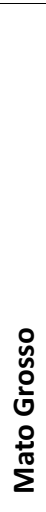 & 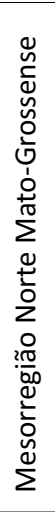 & 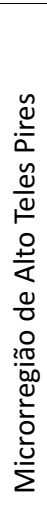 & $\begin{array}{l}\frac{n}{\pi} \\
\frac{\pi}{\pi} \\
\mathbb{n} \\
\stackrel{n}{0} \\
\stackrel{\Xi}{\Sigma}\end{array}$ & 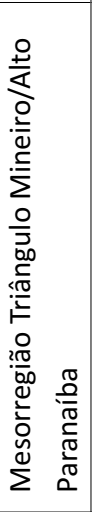 & 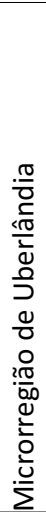 \\
\hline
\end{tabular}




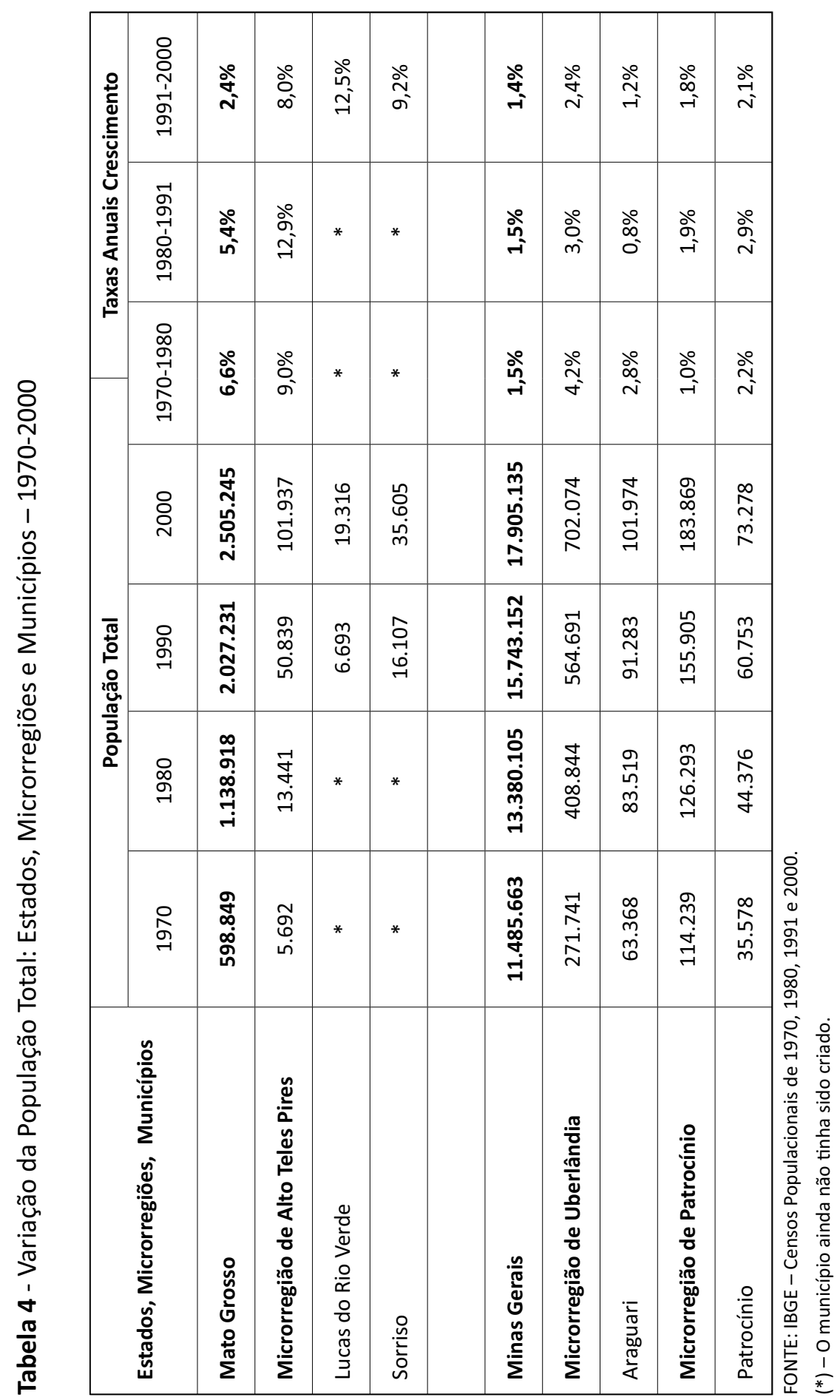


Tabela 5 - Origem de migrantes nos municípios de Sorriso e Lucas do Rio Verde/MT 1995-2000

\begin{tabular}{|c|c|c|c|c|}
\hline Estado de Residência em 31/07/2000 & Lucas do Rio Verde & & Sorriso & \\
\hline População total & 19.316 & $100 \%$ & 35.604 & $100 \%$ \\
\hline Nascidos depois de 1995 & 2.168 & $11 \%$ & 4.016 & $11 \%$ \\
\hline Residentes no estado em 1995 & 13.458 & $70 \%$ & 24.563 & $69 \%$ \\
\hline Não residentes no estado em $1995 *$ & 3.690 & $19 \%$ & 7.026 & $20 \%$ \\
\hline \multicolumn{5}{|l|}{ Estado de residência anterior } \\
\hline Paraná & 1.148 & . & 1.554 & \\
\hline Rio Grande do Sul & 728 & & 866 & \\
\hline Santa Catarina & 440 & & 969 & \\
\hline Mato Grosso do Sul & 167 & & 768 & \\
\hline São Paulo & 157 & & 443 & \\
\hline Rondônia & 105 & & 176 & \\
\hline Pará & 113 & & 251 & \\
\hline Goiás & 78 & & 145 & \\
\hline Maranhão & 82 & & 208 & \\
\hline Outros Estados & 39 & & 306 & \\
\hline Ignorado & 633 & & 1.332 & \\
\hline
\end{tabular}

FONTE: IBGE - Censo Populacional 2000

*- Inclui os que migraram antes de 1995 
Tabela 6 - Origem de migrantes nos municípios de Araguari e Patrocínio/MG 1995-2000

\begin{tabular}{|c|c|c|}
\hline Estado de Residência em 31/07/2000 & Araguari & Patrocínio \\
\hline População Total & 101.974 & 73.278 \\
\hline Nascidos depois de 1995 & 8.089 & 7.165 \\
\hline Residentes no estado em 1995 & 93.885 & 66.113 \\
\hline \multicolumn{3}{|l|}{ Não residentes no estado em 1995 * } \\
\hline \multicolumn{3}{|l|}{ Estado de Residência Anterior } \\
\hline Goiás & 1.109 & 281 \\
\hline São Paulo & 863 & 686 \\
\hline Paraná & 611 & 382 \\
\hline Ceará & 495 & 37 \\
\hline Pará & 217 & 6 \\
\hline Distrito Federal & 179 & 178 \\
\hline Santa Catarina & 135 & 20 \\
\hline Rio de Janeiro & 106 & 33 \\
\hline Mato Grosso do Sul & 103 & 40 \\
\hline Tocantins & 101 & 18 \\
\hline Maranhão & 77 & \\
\hline Mato Grosso & 63 & 98 \\
\hline Pernambuco & 50 & 14 \\
\hline Bahia & 49 & 307 \\
\hline \multirow[t]{2}{*}{ Rio Grande do Sul } & 43 & 42 \\
\hline & 39 & \\
\hline
\end{tabular}

FONTE: IBGE - Censo Populacional 2000

*- Inclui os que migraram antes de 1995 


\section{Notas}

1 - O Cerrado está distribuído, principalmente, pelo Planalto Central Brasileiro, nos estados de Goiás, Tocantins, Mato Grosso, Mato Grosso do Sul, parte de Minas Gerais, Bahia e Distrito Federal, abrangendo 196.776 .853 ha. Há outras áreas de Cerrado, chamadas periféricas, que são transições com os biomas Amazônia, Mata Atlântica e Caatinga.

O Cerrado contém, basicamente, dois estratos: um superior, formado por árvores e arbustos dotados de raízes profundas que lhes permitem atingir o lençol freático, situado entre $15 \mathrm{e}$ 20 metros; e um inferior, composto por um tapete de gramíneas de aspecto rasteiro, com raízes pouco profundas, no qual a intensidade luminosa que as atinge é alta, em relação ao espaçamento. Na época seca, este tapete rasteiro parece palha, favorecendo, sobremaneira, a propagação de incêndios.

2 - A Caatinga é uma cobertura vegetal brasileira endêmica, uma vez que as suas espécies não são encontradas em outra parte do mundo. É uma cobertura vegetal típica do clima tropical semiárido e, devido à escassez de água, as plantas que integram a Caatinga são xerófilas, espécies que se adaptam a essas condições. As cactáceas, por exemplo, possuem espinhos no lugar de folhas, para que haja uma diminuição no processo de evapotranspiração. Já as caducifólias, isto é, espécies vegetais que perdem as folhas em determinados períodos do ano, realizam esse processo para não perder água.

3 - Essas áreas foram objeto de diversas políticas públicas orientadas ao desenvolvimento de uma agricultura empresarial no cerrado brasileiro, através de diferentes programas do governo federal e estadual no início dos anos 1970 e que foram se sucedendo e substituindo ao longo da década. O POLOCENTRO, programa criado em 1975, que tinha como objetivo incentivar a ocupação racional das áreas de cerrado, em 1979 cederia lugar ao PRODECER que se impõe com vários programas subsidiários (OLIVEIRA, 1991).

4 - Nos anos 1970, o antigo estado de Mato Grosso não havia ainda sido segmentado em dois estados: Mato Grosso, correspondente ao norte do estado primitivo e, Mato Grosso do Sul, à sua parte sul, o que aconteceu em 1ㅇ de janeiro de 1979.

5 - Nos últimos dez anos tem aumentado significativamente a importância de outros produtos em outros municípios da região. Às experiências de reflorestamento já existentes, soma-se, entre outras, os cultivos de hortifrutigranjeiros, o cultivo da cana-de-açúcar, além do tradicional milho, agora cultivado em novas bases, ao lado da modernização da também tradicional pecuária.

6 - A pesquisa de que este artigo é um dos resultados é parte de projeto maior - "Sociedade e economia do agronegócio" - desenvolvido pela UFRJ e pela UFFRJ, coordenado por Beatriz Heredia, Leonilde Medeiros, Moacir Palmeira e Sergio Pereira Leite, contando com a participação de 19 pesquisadores. O projeto tem suporte financeiro da Fundação Ford, do CNPq e da FAPERJ. Além de estudos etnográficos, a pesquisa comporta um estudo socioeconômico em nível macro e micro e a análise das instituições e atores políticos envolvidos.

7 - O estudo realizado cobriu exaustivamente essas regiões, mas, para efeito deste artigo, usaremos, sobretudo, dados referentes aos municípios que sediam seus principais núcleos urbanos: Sorriso e Lucas do Rio Verde para a soja, na microrregião de Alto Teles Pires, em Mato Grosso; e Patrocínio e Araguari para o café, na mesorregião do Triângulo Mineiro/Alto Paranaíba, em Minas Gerais.

8 - Esta classificação social das pessoas de acordo com o seu local de nascimento ou origem já havia sido assinalada por Pierre Monbeig nas áreas de expansão do café no estado de São Paulo no final dos anos 1930, onde à contraposição entre "paulistas", identificados com o cultivo do café e "mineiros", associados à "agricultura de autossubsistência" e à criação de suínos, que 
antecediam o plantio de cafezais, iria somar-se aquela entre "paulistas", tomados como tais os grandes produtores de café, e "baianos", termo usado para designar os que trabalhavam nos cafezais, em sua maioria vindos do Nordeste (MONBEIG, 1984).

9 - A categoria "gaúcho" já foi objeto de atenção de alguns pesquisadores. Maristela Andrade (2008) para Maranhão; Rogério Haesbaert (1997) para Bahia; Christine Chaves (2003) para Minas Gerais e, antes, José Vicente Tavares dos Santos (1993) e Luis Roberto Cardoso de Oliveira (1993) para Mato Grosso.

10 - O que estamos afirmando, vale principalmente para os municípios sobre os quais estamos centrando nossa análise. Como, em termos numéricos, há variações importantes entre municípios do Triângulo, onde é notável, além da grande presença de pessoas nascidas em municípios de outras regiões de Minas Gerais, a frequência de nascidos no vizinho estado de Goiás, seria preciso refinar essa análise para podermos fazer afirmações mais genéricas.

11 - Parece importante no entendimento desse ponto (algo que não pode ser desenvolvido plenamente nos limites deste artigo) considerar que esses migrantes vêm das chamadas "áreas coloniais" do Rio Grande do Sul. Via de regra, são descendentes dos imigrantes italianos e alemães que, a partir de meados do século XIX, se instalaram naquele estado, como também em outros da Região Sul. Localmente e em certos tipos de situação não se dizem e não são vistos como "gaúchos", mas sim "de origem", opondo-se a "brasileiros" ou "caboclos". Mas, sobretudo, são famílias que, antes da soja e dos cerrados, já se espalhavam pelos estados vizinhos (Santa Catarina e Paraná) sempre como colonos enfrentando a fragmentação de suas propriedades, operando sobre um território que não respeitava (e que parece continuar a não respeitar hoje, tanto lá quanto nas áreas de expansão da soja ou de outros produtos) a divisa entre estados da Federação.

12 - Eles próprios incluindo desde representantes de grupos econômicos mais amplos até os que operam com "empresas familiares".

13 - Em assentamento na área pesquisada em MT, os assentados consideravam como pequeno produtor quem possuía uma área de 350 ha.

14 - Pensamos em ex-colonos gaúchos que ascenderam economicamente como produtores de soja em Mato Grosso, mas que se recusam a ampliar seu negócio por considerarem que as necessidades da família já estão contempladas.

15 - Não dispomos até agora de informações desse tipo para os baianos do Triângulo Mineiro, por terem as pesquisas se restringido até o momento à própria região, não tendo sido visitados os municípios de origem dos "baianos". Mas encontramos pelo menos um caso de sucesso econômico e social de um baiano que de safrista do café e recrutador de mão-de-obra em seu estado natal para os cafezais do Triângulo tornou-se proprietário e figura de destaque em um dos municípios estudados. Cf. Souza Júnior,2009.

\section{Referências}

ANDRADE, Maristela de Paula. Os Gaúchos descobrem o Brasil. Projetos Agropecuários contra a Agricultura Camponesa. São Luiz: EDUFMA, 2008.

BERNARDES, Júlia Adão. Circuitos espaciais da produção na fronteira agrícola moderna: BR-163 mato-grossense. In: BERNARDES, J. A e FREIRE FILHO, O. L. Geografias da Soja BR-163. Fronteiras em Mutação. Rio de Janeiro: Ed. Arquímedes, 2005.

CARDOSO DE OLIVEIRA, Luis R. Colonização e diferenciação: os colonos de Canarana. Dissertação de Mestrado, PPGAS/MN/UFRJ, Rio de Janeiro, 1981.

CHAVES, Christine. Festas da Política. Uma etnografia da modernidade no sertão (Buritis-M). 
Rio de Janeiro: Relume Dumará, 2003.

DESCONSI, Cristiano. A Marcha dos "pequenos" proprietários rurais no Mato Grosso: um estudo a partir da trajetória de migrantes do sul do Brasil para a microrregião de Alto Teles Pires. Dissertação de Mestrado, CPDA/UFRRJ, Rio de Janeiro, 2009.

HAESBAERT, Rogério. Des-territorialização e identidade. A rede "gaúcha" no Nordeste. Niterói: Ed. UFF, 1997.

IBGE 2004 - Produção Agrícola Municipal, Censos 1970-2000. www.ibge.gov.br

IBGE - Censos Populacionais de 1970, 1980, 1991 e 2000. www.ibge.gov.br

MARTINE, George. O significado demográfico da fronteira agrícola. Espaço e Debates. Ano IV, no $13,1984$.

MONBEIG, Pierre. Pioneiros e fazendeiros de São Paulo. São Paulo: Hucitec/Polis, 1984.

OLIVEIRA, Celia R. G. A frente cafeicultora em Araguari-MG. Dissertação de Mestrado, FFLCH, Universidade de São Paulo, São Paulo, 1991.

RUMSTAIN, Ariana. Peões no trecho: estratégias de deslocamento de trabalhadores no Mato Grosso. Dissertação de Mestrado, PPGAS/MN/UFRJ, Rio de Janeiro, 2009.

SOUZA JÚNIOR, Haiton Pinheiro. O lugar do progresso: famílias, trabalho e sociabilidade em uma comunidade de produtores de café do Cerrado Mineiro. Dissertação de Mestrado, PPGSA/IFCS/UFRJ, Rio de Janeiro, 2009.

TAVARES DOS SANTOS, José Vicente. Matuchos Exclusão e Luta. Do Sul para a Amazônia. Petrópolis: Vozes, 1993.

SAES, Maria Sylvia Macchione. O agronegócio café do Brasil no mercado internacional. Revista FAE Business, № 9, setembro, 2004.

\section{RESUMO}

No Brasil, as áreas de expansão do chamado agronegócio são áreas de forte expansão demográfica. Como mostram as estatísticas, há na base desse processo fluxos migratórios de outras regiões do país. A pertinência dessas informações estatísticas pode ser constatada num contato mesmo que superficial com essas áreas, quando observamos que o "mapa" de posições sociais elaborado pelos que aí vivem remete ao local de nascimento efetivo ou suposto das pessoas ou grupos a que estão se referindo: "gaúchos" e "maranhenses", na área de soja, em Mato Grosso; "paulistas", "paranaenses" e "baianos", na área de expansão do café, no Triângulo Mineiro.

Tal constatação tem levado os estudiosos a estabelecer conexões causais lineares: abrindo perspectivas de lucro ou de emprego, o agronegócio estaria atraindo excedentes populacionais de outras regiões, repetindo o que já se passara, em outros momentos históricos, noutras partes do país. Pesquisas de campo, integradas em um projeto comparativo que vimos realizando naqueles dois estados, apontam para uma realidade mais complexa. Os fluxos migratórios não são necessariamente complementares. Entender essa movimentação constante e esse cruzamento de fluxos passa, a nosso ver, por entender as estratégias de reprodução social operadas pelas famílias envolvidas nesses diferentes movimentos, evitando as classificações convencionais que separam migrações sazonais e migrações definitivas; migrações de curta distância e migrações de longa distância; etc., bem como as interpretações que, procurando estabelecer grandes elos explicativos, acabam simplesmente repetindo e consagrando, através da ideologia do "pioneirismo" ou similares, as formulações dos que controlam o chamado agronegócio.

Palavras-chave: fluxos migratórios; migrações; sociedades do agronegócio. 


\begin{abstract}
The expansion areas of the so called agribusiness in Brazil have strong demographic growth. In the root of this process, accordingly to the statistics, are the migration fluxes from other regions of the country. The coherence of these statistical data can be easily observed in any contact, even superficial, with these areas when we see that the social position "map" elaborated for those who live there refers to the actual birth place or supposed by the people or groups to which they are referring: "gauchos" (from Southern Brazil, more specifically from the state of Rio Grande do Sul) and "maranhenses" (from the state of Maranhão) in the soybean area of Mato Grosso; "paulistas" (from the state of São Paulo), "paranaenses" (from the state of Paraná) and "baianos" (from Bahia) in the expansion area of coffee in the Triângulo Mineiro.

This conclusion has led researchers to establish linear causal connections: opening profit and job perspectives, the agribusiness would attract population excess from other regions, repeating what had already happened in other historical moments and other parts of the country. The performed fieldwork, integrated in a comparative Project, in those two states including the soy region of Mato Grosso and the coffee region of the Triângulo Mineiro-Alto Paranaíba in Minas Gerais, indicates a more complex reality. The migratory fluxes are not necessarily complementary. To understand this constant movement and crossing of various streams goes through, in our mind, understanding the strategies of social reproduction practiced by the involved families in these various movements, avoiding conventional classifications, which separate seasonal and definitive migrations, short- and long-distance migrations, and so on, as well as interpretations that, searching to establish wide explanatory links, simply end up by repeating and consecrating, through the ideology of "pioneerism" or similar, the formules of by those who control the so-called agribusiness.
\end{abstract}

Keywords: migratory fluxes; migrations; agribusiness society. 